\title{
Synaptic Transmission Mediated by Single Club Endings on the Goldfish Mauthner Cell. I. Characteristics of Electrotonic and Chemical Postsynaptic Potentials
}

\author{
Jen-Wei Lin ${ }^{\mathrm{a}}$ and Donald S. Faber \\ Department of Physiology, State University of New York at Buffalo, Buffalo, New York 14214
}

Simultaneous pre- and postsynaptic intracellular recordings, combined with HRP injections, were used to study the properties of junctional transmission between club endings of saccular nerve afferents and the Mauthner (M-) cell in goldfish. All endings were electrotonically coupled to the M-cell, but impulses in less than $20 \%$ of the afferents produced chemically mediated excitatory postsynaptic potentlals as well. There were no differences between the coupling potentials of those endings that mediated chemical transmission and those that did not, and presynaptic injections of HRP confirmed that in both cases the studied fibers terminated on the $M$-cell as single club endings. Since electron microscopic studies (Nakajima, 1974; Kohno and Noguchi, 1986; Tuttle et al., 1986) have consistently revealed structural correlates of chemical synapses in all the endings, we propose that the chemical synapses in the majority of the club endings are functionally silent.

The electrotonic coupling at these junctions was characterized on the basis of coupling coefficients and DC transfer resistances. Coupling coefficients for anti- and orthodromic action potentials averaged 0.076 and 0.011 , respectively. The transfer resistances measured with injections of constant-current pulses were the same in both directions $(\sim 18.6$ $k \Omega$ ), indicating the junctions do not rectify. Two separate calculations of the gap junctional resistance indicated that it is in the range of $6.7-35.8 \mathrm{M} \Omega$, with a mean value of $\mathbf{1 5 . 5}$ $M \Omega$. This calculated junctional resistance corresponds to 670 open gap junction channels, assuming a single-channel conductance of $100 \mathrm{pS}$. As that estimate is about 2 orders of magnitude smaller than the number of the presumed morphological correlates of the channels, i.e., intramembranous particles observed with the technique of freeze-fracture (Kohno and Noguchi, 1986; Tuttle et al., 1986), we conclude that only a small fraction of the morphologically observed channels are open at any time.

The characteristics of the chemically mediated EPSPs were

Received Apr. 28, 1987; revised Sept. 21, 1987; accepted Sept. 23, 1987.

We thank Julie Lakatos for graphics, Jan Jordan for typing the manuscript, and Dr. M. V. L. Bennett for critical comments during these studies. This work was supported in part by NIH Grants NS15335 and NS21848.

A portion of this research was submitted by J.-W.L. in partial fulfillment of the requirements tor the degree of Doctor of Philosophy at the State University of New York, Buffalo, NY

Correspondence should be addressed to Dr. Faber, Department of Physiology, Neurobiology Laboratory, State University of New York, 313 Cary Hall, Buffalo, NY 14214.

a Present address: Department of Physiology and Biophysics, New York University Medical Center, 550 First Avenue, New York, NY 10016

Copyright (C) 1988 Society for Neuroscience $0270-6474 / 88 / 041302-11 \$ 02.00 / 0$ as follows: amplitude, $0.139 \pm 0.075 \mathrm{mV}$ (mean $\pm \mathrm{SD} ; \boldsymbol{n}=$ 16); latency from onset of the coupling potential, $636+26$ $\mu \sec (n=24) ; 10-90 \%$ rise time, $244 \pm 33 \mu \sec (n=14)$ and decay time constant, $1.32 \pm 0.51 \mathrm{msec}(n=6)$. The decay phase was fit by a single exponential, and its time constant presumably is the same as that of the underlying conductance change since the M-cell's membrane time constant is significantly faster, $0.3-0.4 \mathrm{msec}$.

Morphologically mixed synapses have been found in both invertebrate and vertebrate nervous systems (Bennett, 1977; Sotelo and Korn, 1978). While these connections mediate dual transmission in some preparations (Martin and Pilar, 1963; Takahashi and Hama, 1965; Rovainen, 1974a, b; Taugner et al., 1978; Hackett and Buchheim, 1984), only electrotonic coupling has becn detected in others (Hama, 1961; Watanabe and Grundfest, 1961; Bennett et al., 1967a, b; Pappas et al., 1971; Zucker, 1972; Lee and Krasne, 1984). Thus, alternative functions have been proposed for the "chemical synapses" found in the latter group (Pappas and Waxman, 1972; Shapovalov, 1980; Tokunaga et al., 1980; Loewenstein, 1981). In addition, since presynaptic cells generally have multiple terminal ramifications, it is often difficult to correlate dual transmission with a single ending.

The connection between saccular nerve fibers and the Mauthner (M-) cell of goldfish provides an ideal preparation to address questions of dual transmission. These fibers terminate on the lateral dendrite of the $\mathrm{M}$-cell as large myelinated club endings (for review, see Nakajima and Kohno, 1978), and ultrastructural studies have shown that a single ending has the structural correlates of both electrotonic and chemical synapses (Robertson et al., 1963; Nakajima, 1974; Kohno and Noguchi, 1986; Tuttle et al., 1986). In addition, a single afferent sends only one branch, with one such ending, to the M-cell (Lin et al., 1983). Earlier physiological investigations of the club endings used eighth nerve stimulation and revealed both electrotonic and chemical postsynaptic potentials in the M-cell (Furshpan and Furukawa, 1962; Furshpan, 1964; Faber et al., 1980). However, this dual transmission could have been due to the action of 2 separate populations of endings, each functioning in one mode. We now have used simultaneous pre- and postsynaptic recordings to characterize basic properties of electrotonic and chemical postsynaptic potentials produced by impulses in single club endings, identified by intracellular dye injections. The results indicate that in control conditions only a small fraction of the club endings mediate dual transmission, with the coupling potentials being appreciably larger than the chemically mediated EPSPs. 
The remaining endings are also coupled to the lateral dendrite, but their chemical synapses are functionally silent.

The correspondence between gap junctions and electrotonic coupling in various tissues has provided a firm basis for the notion that the former establish a direct pathway for intercellular communication of both metabolic and electrical signals (Bennett, 1977; Loewenstein, 1981). For example, combined morphological and physiological studies of coupled cells have demonstrated that gap junctions, or the packing density of the corresponding intramembranous particles observed in freeze fracture, are modified in parallel with the degree of electrotonic coupling (Barr et al., 1965; Asada and Bennett, 1971; Pappas et al., 1971; Johnson et al., 1974; Peracchia and Dulhunty, 1976; Peracchia, 1977; Flagg-Newton et al., 1981). However, attempts to make quantitative correlations of the level of coupling with its morphological substrate have not been as successful. Ideally, it should be possible to estimate single-channel conductance from the measured junctional conductance and the number of channels, i.e., intramembranous particles, observed morphologically, if the percentage of the open channels is known. The few attempts in this direction, based on the assumption that all the channels observed morphologically were open (Loewenstein, 1975; Bennett, 1977; Haas et al., 1983), provided a wide range of channel conductances, from 10 to $1000 \mathrm{pS}$. On the other hand, recent measurements with the patch-clamp technique indicate that the single gap junctional conductance is about 100$150 \mathrm{pS}$ (Neyton and Trautmann, 1985, 1986; Spray et al., 1986; Veenstra and DeHaan, 1986), and it is likely that the earlier assumption of $100 \%$ channel opening is not justified. In the case of the club endings on the M-cell lateral dendrite, our calculations of gap junctional resistance, together with recent measurements of the number of related intramembranous particles (Kohno and Noguchi, 1986; Tuttle et al., 1986), suggest that only $1-3 \%$ of the junctional channels are conducting.

\section{Materials and Methods}

Electrophysiology and histology. Goldfish (Carassius auratus), 10-12 $\mathrm{cm}$ long, were perfused through the mouth with tap water containing anesthetic (70 mg/liter MS222) and immobilized with $d$-tubocurarine injected intramuscularly ( $1-3 \mu \mathrm{g} / \mathrm{g}$ body weight). Surgical and recording techniques were generally similar to those described previously (Furshpan and Furukawa, 1962; Korn and Faber, 1975). However, the head was rotated laterally so that the entry of the saccular fibers into the brain could be visualized directly.

Two microelectrodes were used for simultaneous pre- and postsynaptic recordings. One (2.5 $\mathrm{M} \mathrm{KCl}, 6-10 \mathrm{M} \Omega$ ) was placed in the M-cell lateral dendrite. In order to record from this region, the axon cap of the M-cell was first located on the basis of an extracellular antidromic spike amplitude $>15 \mathrm{mV}$ (Furshpan and Furukawa, 1962). The electrode was then withdrawn, moved at least $250 \mu \mathrm{m}$ laterally, and inserted into the lateral dendrite. Such a distal recording site, with its final distance being 280-320 $\mu \mathrm{m}$ from the axon cap, is well within the saccular fiber termination field, which starts $225 \mu \mathrm{m}$ lateral to the axon cap and extends distally for $250 \mu \mathrm{m}$ (Lin et al., 1983). Specifically, the electrode was about $80 \mu \mathrm{m}$ distal to the proximal margin of the termination field and $170 \mu \mathrm{m}$ proximal to its distal margin. The second electrode $(1.25 \mathrm{M}$ $\mathrm{KCl}, 30-40 \mathrm{M} \Omega$ ) was used for recording from and stimulating individual saccular afferents outside the brain. Fibers projecting to the M-cell could be identified by the presence of electrotonic coupling potentials in the cell. The final distance between the tips of the 2 electrodes varied from 600 to $800 \mu \mathrm{m}$. "Cross-talk" between the 2 was minimized by grounding a silver coat applied to the presynaptic electrode and by placing grounded aluminum foil between them.

Experimental data were recorded on tape for later analysis, and a Nicolet 1074 computer was used for on-line signal averaging. In some cases, the data were digitized for signal averaging and time course analyses with an INDEC data acquisition system interfaced with a DEC
LSI-11/23 computer. Fluctuations in background noise were measured from photographs of individual traces or from digitized traces.

In order to identify the type of saccular terminals that were studied physiologically, presynaptic intraccllular injections of HRP were used in some experiments. The electrode tip was first filled with the vehicle solution used to dissolve HRP $(0.5 \mathrm{M} \mathrm{KCl}, 0.05 \mathrm{~m}$ Tris $\mathrm{HCl}$-buffer, $\mathrm{pH}$ 8.5 ), and then a $10 \%$ HRP solution was added by back-filling. A period of 8-12 hr was necessary for HRP to diffuse to the tip. The final resistance of these electrodes ranged from 40 to $60 \mathrm{M} \Omega$. At $1-2 \mathrm{hr}$ after the HRP injection, the fish were perfused with $2.5 \%$ glutaraldehyde and $1 \%$ paraformaldehyde in $0.1 \mathrm{~m}$ sodium cacodylate solution. The brains were embedded in gelatin-albumin, sectioned by vibratome $(30-50 \mu \mathrm{m})$, and then reacted for HRP (Adams, 1981). All sections were counterstained with Neutral red. To identify and localize the stained synaptic ending, the $\mathrm{M}$-cell soma, lateral dendrite, and the stained fiber were reconstructed from serial horizontal sections.

Estimation of gap junction resistance. To estimate junctional resistance, the coupling coefficients in both the anti- and orthodromic directions and the transfer resistance were measured (Bennett, 1966). The coupling coefficients are defined as

$$
\begin{aligned}
& K_{\mathrm{sm}}=V_{\mathrm{m}} / V_{\mathrm{s}}=R_{\mathrm{m}} /\left(R_{\mathrm{m}}+R_{\mathrm{j}}\right), \\
& K_{\mathrm{ms}}=V_{\mathrm{s}} / V_{\mathrm{m}}=R_{\mathrm{s}} /\left(R_{\mathrm{s}}+R_{\mathrm{j}}\right),
\end{aligned}
$$

where $K_{\mathrm{sm}}$ is the orthodromic coupling coefficient and is equal to the ratio of the voltage recorded in the M-cell $\left(V_{\mathrm{m}}\right)$ to the amplitude of action potential of the saccular fiber $\left(V_{\mathrm{s}}\right)$. By analogy, $K_{\mathrm{ms}}$ is the antidromic coupling coefficient. $R_{\mathrm{j}}$ represents the junctional resistance, and $R_{\mathrm{m}}$ and $R_{\mathrm{s}}$ are, respectively, the $\mathrm{M}$-cell and saccular fiber extrajunctional resistances. $R_{\mathrm{m}}$ can be approximated by the measured input resistance of the M-cell, since this neuron is coupled to numerous afferents and the inclusion of one club ending should have a negligible effect on this parameter.

The transfer resistance in either direction, $R_{t}$, is

$$
R_{\mathrm{t}}=V_{\mathrm{m}} / I_{\mathrm{s}}=V_{\mathrm{s}} / I_{\mathrm{m}}=\left(R_{\mathrm{m}} R_{\mathrm{s}}\right) /\left(R_{\mathrm{m}}+R_{\mathrm{j}}+R_{\mathrm{s}}\right),
$$

where $I_{\mathrm{s}}$ is the intensity of current injected into the saccular fiber, and $I_{\mathrm{m}}$ is the current injected into the M-cell.

$R_{\mathrm{j}}$ can be determined with 3 separate approaches. First, it can be estimated directly from equation (1), since $R_{\mathrm{m}}$ is effectively equal to the measured M-cell input resistance. Second, $R_{\mathrm{j}}$ can be estimated from equation (2), if $R_{\mathrm{s}}$ is also effectively the measured input resistance of a saccular fiber, $R_{\mathrm{s}}{ }^{\prime}$. That assumption is valid only when $R_{\mathrm{s}} \ll R_{\text {j }}$, i.e., if $K_{\mathrm{m}}$ is small.

Third, it is possible to solve equations 1-3 simultaneously, in order to calculate $R_{\mathrm{j}}$ directly:

$$
\begin{aligned}
R_{\mathrm{j}} & =R_{\mathrm{t}}\left(1-K_{\mathrm{sm}} K_{\mathrm{ms}}\right) / K_{\mathrm{ms}} K_{\mathrm{sm}} \\
R_{\mathrm{m}} & =R_{\mathrm{t}}\left(1-K_{\mathrm{sm}} K_{\mathrm{ms}}\right) / K_{\mathrm{ms}}\left(1-K_{\mathrm{sm}}\right) \\
R_{\mathrm{s}} & =R_{\mathrm{t}}\left(1-K_{\mathrm{sm}} K_{\mathrm{ms}}\right) / K_{\mathrm{sm}}\left(1-K_{\mathrm{ms}}\right)
\end{aligned}
$$

The extrajunctional resistances, $R_{\mathrm{n}}$ and $R_{\mathrm{s}}$, thus calculated can be compared with the input resistances measured experimentally.

These equations are based on a DC coupling model for a pair of isolated and coupled spherical cells (Bennet, 1966), while we have generally measured the coupling coefficients mediated by impulses. Possible errors introduced by this approximation will be further evaluated before junctional resistance is estimated in the Results.

Measurements of coupling potential amplitudes. The mean and variance of coupling potentials produced by impulses in one afferent were calculated from measurements of photographs of individual traces or digitized traces in the computer. Background noise was estimated by measuring the amplitudes of 0.5 or $1 \mathrm{mV}$ calibration pulses, timed to occur at the beginning of each trace. The variance of the background noise was then subtracted from that of the coupling potentials. That is,

$$
v_{\mathrm{s}}=v_{\mathrm{d}}-v_{\mathrm{b}}
$$

where $v_{\mathrm{b}}$ is the variance of the background noise, $v_{\mathrm{d}}$ the variance of the potential measured from individual traces, and $v_{s}$ the corrected variance. The latter was then used for statistical analyses. The time window over which the potentials were measured remained constant for both noise and signal such that the "bandwidth" of the measurements was the same. In some experiments, the variance measured with calibration pulses was compared with that measured from baseline. The latter consistently had a mean of zero and the same variance as that obtained from the calibration pulse measurements. 


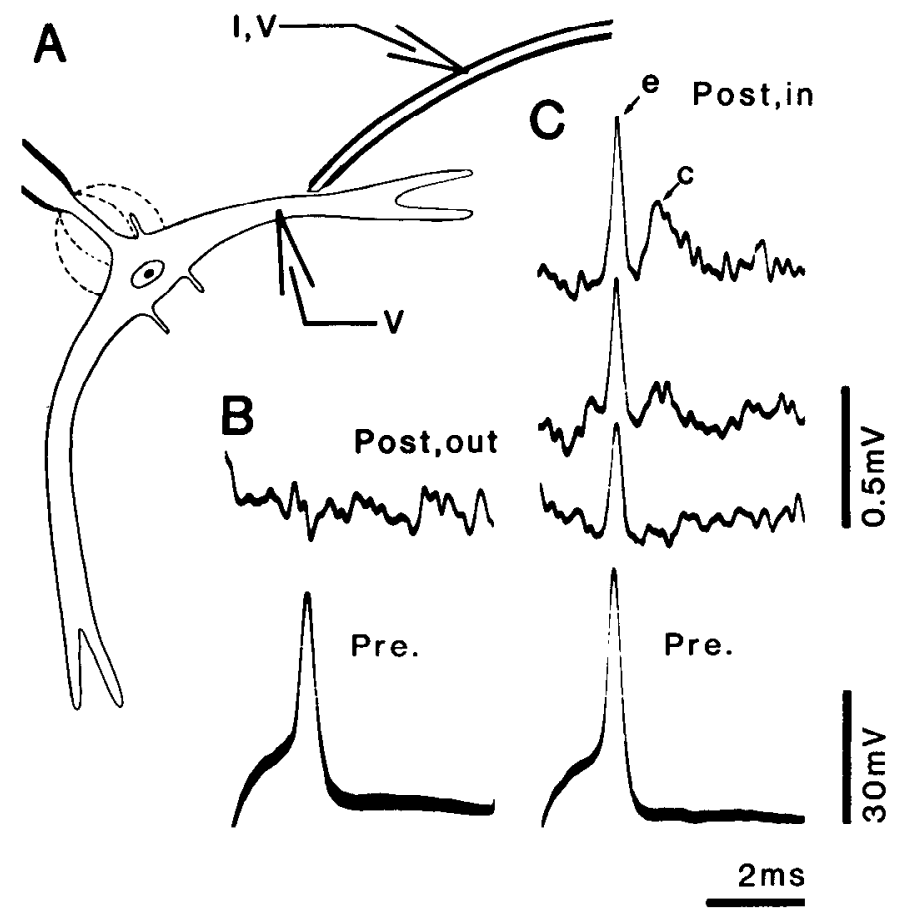

Figure 1. Experimental arrangement and an example of the transsynaptic recordings. $A$, Simultaneous intracellular voltage $(V)$ recordings were obtained from the lateral dendrite and a saccular fiber. The presynaptic electrode, used for current $(I)$ injections also, was outside the medulla near the point of entry of the saccular nerve, while the $\mathrm{M}$-cell was penetrated about $280-320 \mu \mathrm{m}$ lateral to the axon hillock. The final distance between the 2 recording sites was typically about $700 \mu \mathrm{m} . B$, When the M-cell electrode was extracellular, impulses in the saccular fiber (lower trace, Pre) did not evoke any measurable potentials (upper trace, Post, out). C, After penetrating the M-cell in the same experiment, a 2-component response could be evoked (upper 3 traces, Post, in) by presynaptic impulses, one of which is illustrated (bottom trace). $e$, electrotonic coupling potential; $c$, chemically mediated excitatory postsynaptic potential.

\section{Results}

The data reported here were obtained by simultaneous intracellular recordings from the $\mathbf{M}$-cell and single saccular fibers. Typically, penetration of the M-cell lateral dendrite was established first, at 280-320 $\mu \mathrm{m}$ lateral to the axon cap; then, a search for the saccular fibers that made synaptic contact with the M-cell began (Fig. 1A). A synaptic connection was identified by the presence of electrotonic coupling potentials evoked by presynaptic impulses (Fig. 1C), and such impulses did not produce any field potential when the M-cell electrode was extracellular (Fig. $1 B$ ). In more than $80 \%$ of the connections thus established, only electrotonic transmission was observed. Dual transmission was detected in the remaining cases (Fig. $1 \mathrm{C}$ ), while chemical transmission alone was never encountered.

\section{Electrotonic coupling}

Action potentials in saccular fibers produced orthodromic coupling potentials in the M-cell lateral dendrite. As shown in the example in Figure $2 \mathrm{Al}$, the coupling potentials had short latencies and rapid time courses. The latency of the coupling potential was generally too short to be measured accurately and its time course was typically similar to that of the presynaptic impulse. The amplitudes of the action potentials shown in this example

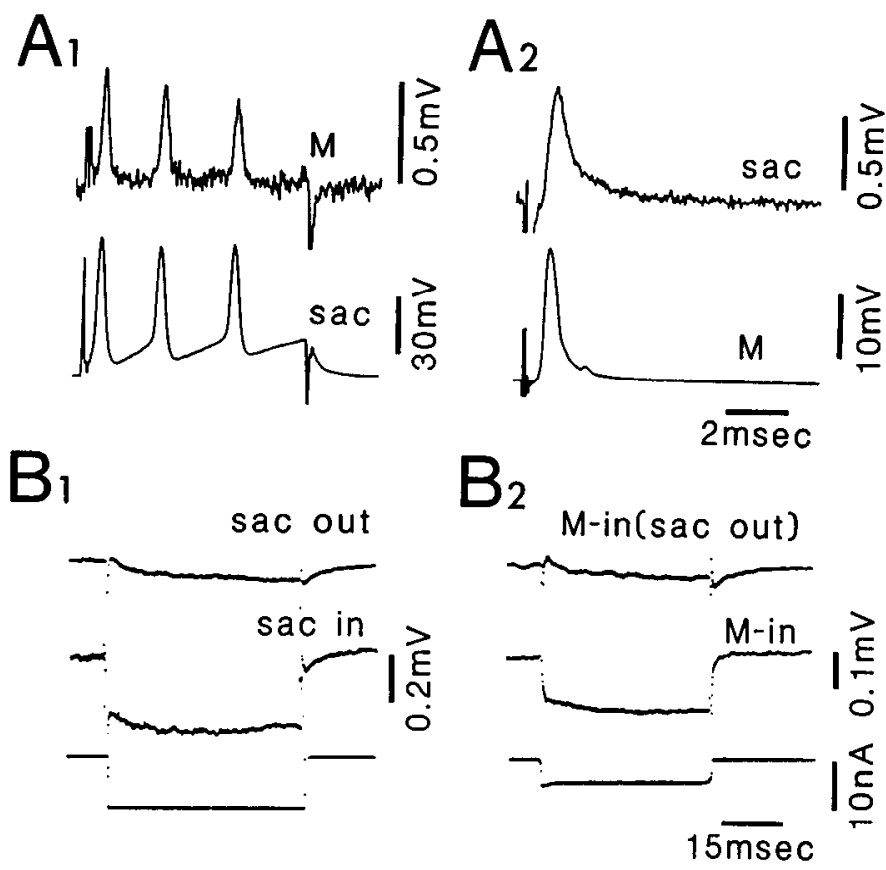

Figure 2. Characteristics of electrotonic coupling between club endings and the M-cell lateral dendrite. $A I$ and $A 2$, Bidirectional coupling of action potentials observed in one experiment. $A 1$, Orthodromic coupling potentials produced in the $\mathrm{M}$-cell lateral dendrite (upper trace, $M$ ) by saccular fiber impulses (lower trace, sac). Both traces are the averages of 11 sweeps, obtained by aligning the third presynaptic impulse. $A 2$, The M-cell antidromic action potential (lower trace) evoked a coupling potential in the presynaptic fiber (upper trace); both traces are the average of 66 records. $B I$ and $B 2$, Coupling potentials recorded in another experiment, using intracellular current injections. $B I$, A hyperpolarizing current pulse of $10 \mathrm{nA}$ (lower trace) injected into the M-cell lateral dendrite produced a hyperpolarization in the fiber and a field potential extracellular to it (upper trace, sac out). Middle trace (sac in), Net transmembrane coupling potential change in the fiber, obtained by subtracting the extracellular field from the response measured intracellularly. Transfer resistance $=32.9 \mathrm{k} \Omega$. B2, Similarly, a $5 \mathrm{nA}$ current pulse injected (lower trace) into the fiber produced a coupling potential in the $\mathrm{M}$-cell lateral dendrite (middle trace, $M$-in), obtained by subtracting the transient potential change in the M-cell produced by current applied extracellular to the fiber (upper trace, $M$-in, sac out) from the coupling potential produced by the intracellular injection. Transfer resistance $28.8 \mathrm{k} \Omega$. Current calibration is the same for $B I$ and $B 2$. All the potential traces in $B$ are averages of 1024 sweeps.

were about $67 \mathrm{mV}$, while those of the coupling potentials averaged $0.53 \mathrm{mV}$, with a coupling coefficient of 0.008 .

In 77 fibers studied, the average value of the orthodromic coupling potential was $0.8 \pm 0.39 \mathrm{mV}$ (mean $\pm \mathrm{SD}$ ) with a range of $0.35-2.04 \mathrm{mV}$. Other fibers that produced coupling potentials in the amplitude range of $100-300 \mu \mathrm{V}$ were difficult to study and were discarded. An average of the coupling coefficients estimated for individual fibers is not considered reliable, since the presynaptic recording quality varied, and the impulse amplitudes thus recorded may not have been a valid indicator of the active potential changes in the terminals. For those connections where the presynaptic impulse amplitude was $>60 \mathrm{mV}$, the coupling coefficient averaged $0.0095(n=5)$. Assuming that impulses at the terminals of the saccular fibers have an amplitude of $75 \mathrm{mV}$, which was the largest impulse ever recorded, the coupling coefficient for the entire population averaged 0.011 .

The gap junctions appeared to be nonrectifying since M-cell antidromic spikes evoked coupling potentials in the saccular 
Table 1. Electrotonic coupling mediated by impulses and current injection

\begin{tabular}{|c|c|c|c|c|c|c|c|}
\hline \multirow[b]{3}{*}{ Fiber } & \multirow{2}{*}{\multicolumn{2}{|c|}{$\begin{array}{l}\text { Coupling coefficient } \\
\text { of action potentials }\end{array}$}} & \multirow{2}{*}{\multicolumn{2}{|c|}{$\begin{array}{l}\text { Transfer resistances }(\Omega) \\
\text { mediated by current injection }\end{array}$}} & \multicolumn{3}{|c|}{ Calculated resistances $(\mathrm{M} \Omega)$} \\
\hline & & & & & \multirow[b]{2}{*}{ Gap junction } & \multirow[b]{2}{*}{ M-cell } & \multirow{2}{*}{$\begin{array}{l}\text { Saccular } \\
\text { fiber }\end{array}$} \\
\hline & Orthodromic & Antidromic & Orthodromic & Antidromic & & & \\
\hline $\mathrm{DCl}$ & 0.0094 & 0.066 & $1.14 \times 10^{4}$ & - & 18 & 0.173 & 1.27 \\
\hline $\mathrm{DC} 2$ & 0.0083 & 0.039 & $2.15 \times 10^{4}$ & $1.97 \times 10^{4}$ & 66 & 0.55 & 2.71 \\
\hline DC3 & 0.0079 & 0.027 & $1.25 \times 10^{4}$ & $1.16 \times 10^{4}$ & 59.9 & 0.476 & 1.63 \\
\hline DC4 & 0.0117 & 0.068 & - & $1.88 \times 10^{4}$ & 23.6 & 0.278 & 1.73 \\
\hline DC5 & 0.0084 & 0.088 & $1.56 \times 10^{4}$ & $1.69 \times 10^{4}$ & 24.5 & 0.208 & 2.35 \\
\hline DC6 & 0.018 & 0.08 & $2.96 \times 10^{4}$ & $2.87 \times 10^{4}$ & 22.8 & 0.418 & 1.98 \\
\hline Mean $\pm S D$ & $0.0106 \pm 0.0039$ & $0.061 \pm 0.024$ & $(1.98 \pm 0.75)$ & $(1.92 \pm 0.72)$ & $35.8 \pm 21.23$ & $0.351 \pm 0.153$ & $1.95 \pm 0.52$ \\
\hline
\end{tabular}

Parameters of electrotonic coupling mediated by impulses and current pulse injections. All data obtained from saccular fibers with resting membrane potential larger than $-55 \mathrm{mV}$ and action potential amplitudes larger than $55 \mathrm{mV}$. For each fiber, both anti- and orthodromic coupling coefficients were measured, and transfer resistance was obtained for at least one direction. The averaged transfer resistances were obtained only from the fibers where DC couplings were measured in both directions. The

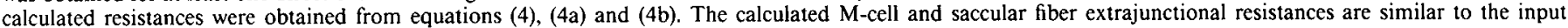
resistances measured experimentally.

fibers, as illustrated in the averaged traces of Figure $2 A 2$. In that case, the antidromic spike had an amplitude of $21 \mathrm{mV}$ in the lateral dendrite and the coupling potential was $0.82 \mathrm{mV}$ in the fiber, giving a coupling coefficient of 0.04 . In contrast to the orthodromic coupling, the time course of the antidromic coupling potential was slower than that of the M-cell antidromic spike, presumably due to the capacitive filtering by the axonal membrane. The amplitude of the antidromic coupling potentials had an average of $1.11 \pm 0.61 \mathrm{mV}(n=42$, range $=0.15-2.3$ $\mathrm{mV}$ ), and the $\mathrm{M}$-cell antidromic spike, recorded in the lateral dendrite, averaged $14.7 \mathrm{mV} \pm 4.6 \mathrm{mV}(n=29)$, with the mean population antidromic coupling coefficient being 0.076 .

Electrotonic coupling could also be demonstrated by direct current injection into either the $\mathrm{M}$-cell or individual saccular fibers. In the example of Figure $2 B 1$, which was obtained from a fiber different from that illustrated in $A 1$ and $A 2$, a $10 \mathrm{nA}$ hyperpolarizing current pulse injected into the M-cell lateral dendrite produced a net potential change of $0.33 \mathrm{mV}$ in the saccular fiber. The field potential, obtained with the saccular fiber electrode located extracellularly, was relatively small. Thus, the net transmembrane potential change, calculated by subtracting the field potential from the coupling potential recorded intracellularly, was slightly less than that recorded intra-axonally (not shown). Orthodromic coupling produced by a presynaptic current injection ( $5 \mathrm{nA})$ at the same junction is demonstrated in Figure $2 B 2$. In this example, the anti- and orthodromic coupling potentials are 0.33 and $0.14 \mathrm{mV}$, respectively, and the transfer resistances in both directions are similar, $29 \mathrm{k} \Omega$ for orthodromic coupling and $33 \mathrm{k} \Omega$ for antidromic coupling. Additional experimental results are described in Table 1 . The general agreement of transfer resistances in the 2 directions provides additional support for the nonrectifying nature of the gap junctions.

Estimation of junctional resistance. In order to estimate gap junctional resistance $\left(R_{\mathrm{j}}\right)$ of the club endings from cquations (1) or (2), it is important to establish that the coupling associated with action potentials approximates that seen with DC potential changes produced by current pulses and to estimate the effects of spatial decay of the signals.

For orthodromic coupling, the fast time constant of the M-cell, $300-400 \mu \mathrm{sec}$, should result in little capacitive attenuation of the fast coupling potentials (Fukami et al., 1965; Furukawa, 1966). This is in agreement with the identical time course of the coupling potentials and the presynaptic impulses (Fig. $2 \mathrm{Al}$ ). The spatial decay of the orthodromic coupling potentials can be estimated on the bases of the known termination field of the club endings, the location of the $\mathrm{M}$-cell recording electrode, and the $M$-cell space constant. Since the recording electrode was normally located about $300 \mu \mathrm{m}$ lateral to the axon cap, the most distal saccular terminal would be about $170 \mu \mathrm{m}$ from the electrode (see Materials and Methods). The estimated space constant for a fast transient generated in the dendrite and conducted toward the soma is 200-300 $\mu \mathrm{m}$ (Furukawa, 1966; Diamond, 1968; Faber et al., 1980). Therefore, in the most extreme case, spatial decay along the dendrite would result in a coupling potential amplitude $43 \%$ of its original value. In reality, the signal attenuation was most likely minimal, as most of the club endings were concentrated at the center of the termination field (Lin et al., 1983) and should have been within 50-70 $\mu \mathrm{m}$ of the M-cell electrode. Furthermore, we have mentioned that the sampling of the orthodromic coupling potentials was biased to larger values, a procedure that would compensate, to a certain degree, for the spatial decay.

The calculation of junctional resistance from orthodromic coupling coefficients (equation 1) also required the previously measured M-cell input resistances, $167 \mathrm{k} \Omega$ (Faber and Zottoli, 1981; Faber and Korn, 1982) and the assumption that the action potential amplitude in the club endings was $75 \mathrm{mV}$. The value used for input resistance was that measured previously at or near the M-cell soma since both a cable model of this neuron (Crank, 1986) and limited experimental results (Faber and Korn, 1986) indicate it is comparable to or only slightly less than the dendritic input resistance. If intradendritic input resistance is significantly greater than expected, this approach would result in an underestimation of $R_{\mathrm{j}}$. The assumption that presynaptic spike height is $75 \mathrm{mV}$ derives from the observation that during the course of some experiments the presynaptic spikes deteriorated at the recording site, but the coupling potential amplitudes remained constant. This observation contradicts the possibility that the presynaptic impulses were passively conducted to the terminal. In addition, the gradual depolarization seen between presynaptic impulses was generally not apparent in the M-cell (Fig. 2Al), an observation that also ruled out purely passive conduction between the recording sites and the terminals. Therefore, either there was at least one additional node between the presynaptic recording electrode and the ending or, 


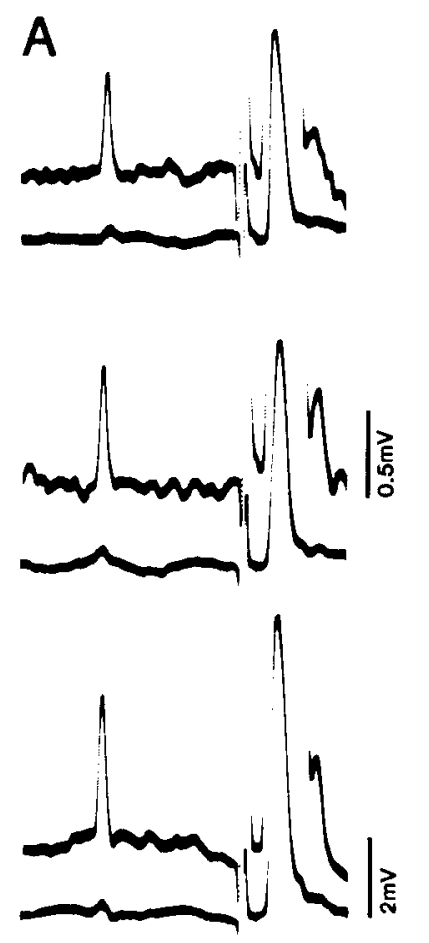

$2 m s e c$

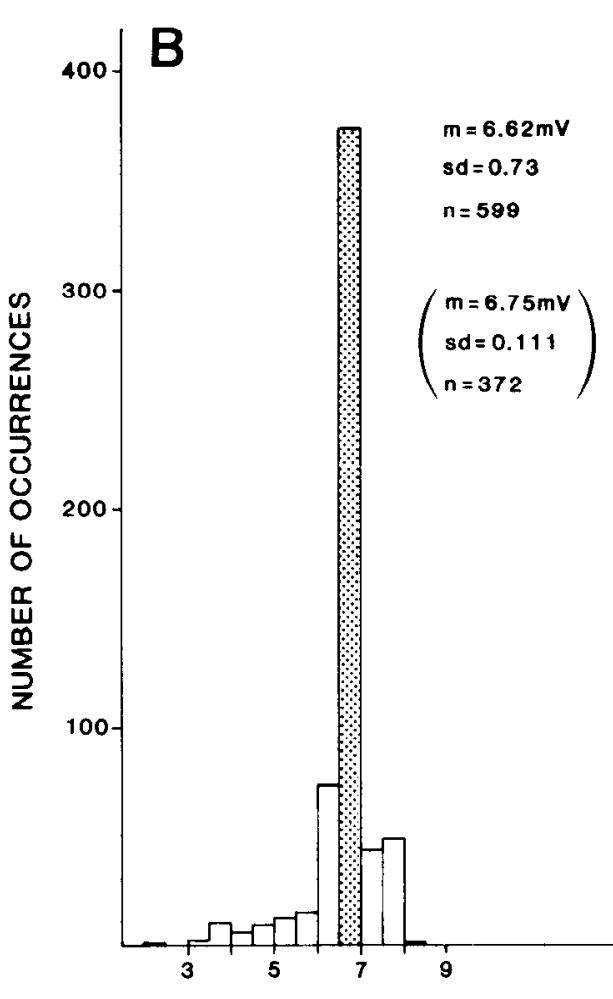

AD ACTION POT.

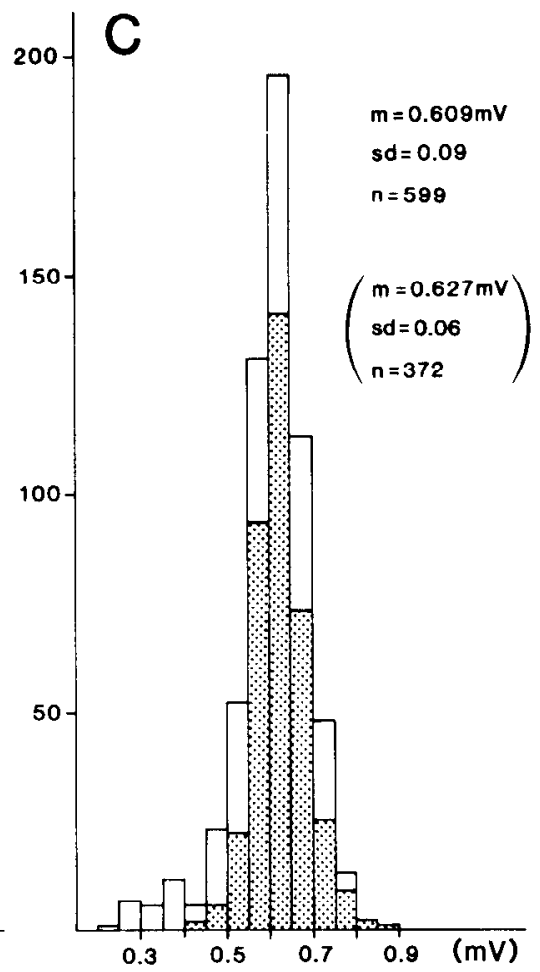

OD COUPLING POTENTIAL

Figure 3. Variations in M-cell input resistance cannot entirely account for fluctuations in orthodromic coupling potential amplitudes. A, Examples of the "cofluctuation" of coupling potentials and M-cell antidromic spikes. Upper and lower traces of each pair are high- and low-gain M-cell recordings to show the respective amplitudes of the coupling potentials and the subsequent antidromic spikes. Note that the amplitudes of the 2 vary in parallel. The $2 \mathrm{mV}$ calibration is for the low-gain traces and the $0.5 \mathrm{mV}$ bar is for the high-gain traces. $B$ and $C$. Amplitude histograms of the M-cell antidromic impulses $(B)$ and the orthodromic coupling potentials $(C)$ with which they were paired. Shaded areas indicate the data selected on the basis of antidromic spikes of a constant amplitude, i.e., the major peak in $B$. Note that the shaded area in $C$ still indicates a significant fluctuation in the amplitudes of the coupling potentials. The SD of the background noise in this example was $0.050 \mathrm{mV}$. In both $B$ and $C$, the upper set of parameters pertain to the full data set, while those in parentheses are for the selected data in the shaded areas. (See text for the correlation analysis of the 2 variables.)

more likely, the terminal region of the club endings was active. For an average orthodromic coupling potential of $0.8 \mathrm{mV}$ (coupling coefficient $=0.0107$ ), the calculated gap junction resistance is $15.5 \mathrm{M} \Omega$. If the maximal spatial decay of the orthodromic coupling pertained for all fibers, this average value would be reduced to $6.6 \mathrm{M} \Omega$, which can be taken as a lower limit for $R_{j}$.

The reliability of the antidromic coupling potential measurement is more difficult to assess because the space constant of the saccular fibers is not known. In addition, since the time course of the antidromic coupling potential is noticeably slower than that of the M-cell antidromic spikes, there must be significant capacitive attenuation (Fig. 2A2). Finally, the extrajunctional resistance $\left(R_{\mathrm{s}}\right)$ of the saccular fibers, which is required for equation (2), can only be approximated by the measurement of axonal input resistance $\left(R_{\mathrm{s}}{ }^{\prime}\right)$, which we found to be $4.2 \pm 0.9$ $\mathrm{M} \Omega(n=6)$. Since the value of $R_{\mathrm{j}}$ estimated from equation (1) is only about 3.7 times larger than $R_{\mathrm{s}}^{\prime}$, the measured axonal input resistance may include a significant contribution from $R_{\mathrm{j}}$. Thus, since equation (2) is applicable only if $R_{\mathrm{s}} \ll R_{\mathrm{j}}$, it was not used to estimate $K_{\mathrm{j}}$.

When impulse coupling coefficients in both directions and the transfer resistance were all measured for the same saccular fiber, it was possible to calculate the junctional resistance from equation (4). With this approach, the calculated junctional resistance ranged from 18 to $66 \mathrm{M} \Omega$, with an average of $35.8 \mathrm{M} \Omega(n=6)$, as indicated in Table 1. The estimate thus obtained for $R_{\mathrm{j}}$ is about twice that obtained from equation (1). This difference is somewhat expected, since the averaged orthodromic coupling potential used for the first method, $0.8 \mathrm{mV}$, was obtained by a biased sampling, where smaller coupling potentials, which would have yielded higher junctional resistances, were discarded. In contrast, the selection of the fibers listed in Table 1 was mainly based on the quality of the presynaptic penetration, rather than the amplitude of the coupling potentials. In addition, spatial decay of potential in the presynaptic fiber introduces some error into this calculation, analogous to that mentioned for the measurements based on orthodromic coupling potentials. Specifically, since the saccular fiber electrode is about $0.75 \mathrm{~mm}$ away from the junctional contact, both $R_{\mathrm{t}}$ and the antidromic coupling coefficient, $K_{\mathrm{ms}}$, were somewhat underestimated. Inspection of equations 2-4 indicates that these errors would be comparable, given the low value of the M-cell input resistance and, therefore, that this method may lead to an overestimate of $R_{j}$. Similar arguments indicate that use of equation $4 \mathrm{~b}$ should lead to an underestimation of the saccular fiber input resistance. Specifically, as $\left(1-K_{\mathrm{sm}} K_{\mathrm{ms}}\right) \sim 1, R_{\mathrm{s}} \sim R_{\mathrm{t}} / K_{\mathrm{sm}}\left(1-K_{\mathrm{ms}}\right)$, and since spatial decay in the afferent fiber causes both $R_{\mathrm{t}}$ and $K_{\mathrm{ms}}$ to be underestimated, the calculated value of $R_{\mathrm{s}}$ should be less than the measured one. In confirmation, when $R_{\mathrm{s}}$ was calculated in this manner, it averaged 1.95 M $\Omega$ (Table 1); this is less than the 
4.2 M $\Omega$ measured experimentally, and it is significantly smaller than the more appropriate value for comparison, which would be the termination resistance and is expected to be twice that measured in the axon (i.e., $8.4 \mathrm{M} \Omega$ ). Thus, the 2 methods used to estimate $R_{\mathrm{j}}$ yield comparable results, with the differences between the 2 being in the expected direction.

Fluctuations of coupling potentials. The amplitudes of coupling potentials recorded in the M-cell fuctuated from trial to trial (Fig. 3). One possible source of this fluctuation is a variation in the input resistance of the M-cell, due, for example, to spontaneous synaptic inputs. To test this possibility, an antidromic stimulus was applied within $6 \mathrm{msec}$ after each orthodromic coupling potential, and the amplitude of the antidromic impulse was used as an indicator of the instantaneous input resistance of the M-cell. An example of this paradigm is shown in Figure $3 \mathrm{~A}$, and it appears that the coupling potentials fluctuated in parallel with the antidromic impulses. The amplitude histograms of the antidromic spike and the coupling potentials recorded together in the M-cell are illustrated in Figure 3, $B$ and $C$, respectively. In this example, a cross-correlation analysis revealed a significant correspondence between the amplitudes of 2 responses (correlation coefficient $=0.696$ ). In $92 \%$ of the fibers studied ( $n=12$ ), there was such a correlation, indicating that fluctuations in the amplitudes of coupling potentials could be attributed to the variations in the $\mathrm{M}$-cell input resistance. This factor was then minimized by selecting only those coupling potentials that were followed by antidromic spikes of a constant amplitude, designated by the shaded areas in the histograms of Figure 3, $B, C$. In this example, the variance of the selected coupling potentials was $3477 \mu \mathrm{V}^{2}$, which was still significantly larger than that of the background noise $\left(2510 \mu \mathrm{V}^{2}\right)$. In addition, the correlation between antidromic impulses and coupling potentials became statistically insignificant after the selection (correlation coefficient $=0.032$ ), suggesting that the 2 variables fluctuated independently in the abscnce of changes in $\mathrm{M}$-cell input resistance. Similar results were obtained in 4 out of 6 fibers tested. This finding may indicate there is an intrinsic variability in the amount of current injected by saccular fiber impulses, which could be due to fluctuations in the gap junctional resistance or to variations in the amplitude of the presynaptic spike. However, when the same approach was used to analyze the fluctuations of antidromic coupling potentials recorded in the saccular fibers, the amplitudes of the coupling potentials evoked by spikes of the same magnitude were more variable than the background noise in only 1 of 5 fibers tested. This observation does not support the notion that variations in junctional conductance contribute to fluctuations in the coupling potentials.

\section{Chemical transmission}

Basic characteristics. Chemically mediated EPSPs were observed in less than $20 \%$ of the saccular fibers studied. When an EPSP was evoked by a presynaptic impulse, it was always preceded by an electrotonic coupling potential, as demonstrated by the example in Figure $4 A$. Since the latency of the coupling potential was extremely short, the EPSP latency was approximated from the beginning of the coupling potential to the foot of the EPSP. In 14 examples, the mean latency was $636 \pm 26$ $\mu \mathrm{sec}$, which is clearly monosynaptic. The avcragc amplitude of the EPSP $(139 \pm 75 \mu \mathrm{V}, n=16)$ is small compared with that of the associated coupling potentials ( $825 \pm 391 \mu \mathrm{V}, n=16)$, which is the same as the mean for the coupling potentials not followed by EPSPs $(800 \pm 390 \mathrm{mV}, n=70)$. Therefore, the degree of electrotonic coupling at those endings that mediate dual transmission and those that do not appears to be the same.

Separation of the EPSP from the electrotonic coupling potential can be demonstrated by repetitive stimulation. Specifically, the EPSP amplitude remains stable at low frequency, 0.7 $\mathrm{Hz}$, and fatigues when the stimulation is repeated at frequencies of $20 \mathrm{~Hz}$ or more (Fig. $4 \mathrm{~B}$ ). Also, the coupling potential recorded at the higher frequency decays rapidly, indicating that it does not appreciably distort the EPSP time course.

The EPSPs mediated by the saccular fibers were quite fast, as shown in Figure 5. In that example, the rise time, measured from 10 to $90 \%$ of the peak amplitude, is $220 \mu \mathrm{sec}$ and the decay time constant is $1.5 \mathrm{msec}$. The exponential nature of the decay phase is illustrated in the expanded plot in the inset, along with the best-fitting, single-exponential decay determined with regression analysis. The rise time and decay time constant averaged $244 \pm 33 \mu \mathrm{sec}(n=16)$ and $1.32 \pm 0.51 \mathrm{msec}(n=6)$, respectively, in those experiments where averaged records revealed a clear EPSP. Given the fast membrane time constant of the M-cell, $\leq 400 \mu \mathrm{sec}$ (Fukami et al., 1965; Furukawa, 1966), the decaying phase of the EPSP probably approximates that of the underlying synaptic conductance change.

No attempts were made to determine either the ionic basis or reversal potential of the EPSP due to difficulties in reliably shifting the membrane potential of the low-resistance M-cell. Since the time available for maintaining the intra-axonal recordings was limited, we did not try to block chemical transmission by reducing extracellular calcium concentration.

Morphological identification of the synaptic terminals studied physiologically. The observation of 2 populations of saccular fibers producing distinctly different physiological responses could imply that these responses were mediated by morphologically different terminals, particularly since we previously found 2 types of saccular endings on the M-cell, club endings and endbulbs (Lin et al., 1983). Intracellular HRP injections of the presynaptic fibers used for these physiological studies allowed us to examine this possibility. In a series of 11 experiments where single saccular fibers coupled to the M-cell were stained, 5 mediated dual transmission, and all of them terminated on the M-cell as large myelinated club endings. Typical results from a fiber that terminated as a club ending and mediated dual transmission are shown in Figure 6. In this case, EPSPs can be clearly identified in the single traces of Figure $6 \mathrm{~A}$, which also demonstrate that the EPSPs are markedly facilitated when short trains of presynaptic impulses are used (Lin and Faber, 1988). A micrograph of the stained terminal in Figure $6 B 1$ shows that it has the characteristics of a large myelinated club ending, and the camera lucida reconstruction of the saccular fiber and part of the M-cell in Figure $6 B 2$ demonstrates the distal location of this terminal. In this experiment, the calculated intradendritic recording site was about $280 \mu \mathrm{m}$ from the axon hillock region or within $50 \mu \mathrm{m}$ of the stained synaptic contact. This spatial relationship is typical for most of the fibers reconstructed after physiological recordings.

Pure electrotonic coupling was observed in the remaining 6 successful staining experiments, and again the injected terminals wcre identificd as club endings in all cases. An example is shown in Figure 7, where the presynaptic impulse produced only coupling potentials in the M-cell. An average of 10 postsynaptic responses failed to expose any EPSP, although this procedure 


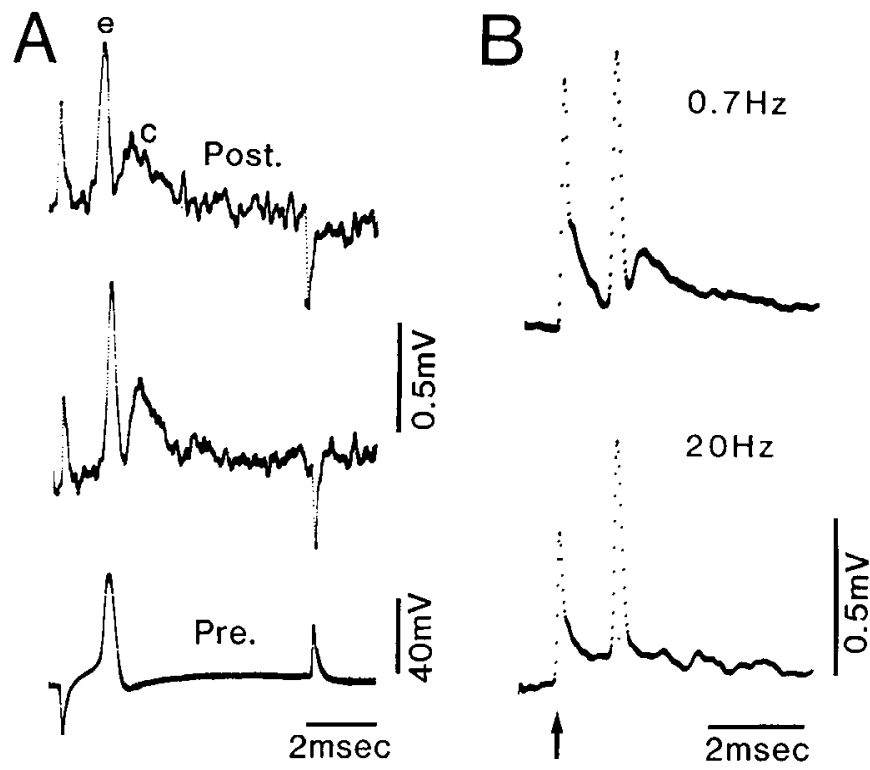

Figure 4. Demonstration of chemical transmission and its frequency dependence. A, Upper 2 traces (Post) show examples of electrotonic coupling potentials $(e)$, followed by chemically mediated excitatory postsynaptic potentials $(c)$ recorded from the $M$-cell lateral dendrite as a result of single impulses in a saccular fiber (bottom trace, Pre). $B$, In a separate experiment, the frequency dependence of chemical transmission was demonstrated by comparing the averaged responses $(n=16)$ evoked with presynaptic stimulus frequencies of $0.7 \mathrm{~Hz}$ (upper trace) and $20 \mathrm{~Hz}$ (lower trace). The amplitude and time course of the coupling potential isolated at $20 \mathrm{~Hz}$ was the same as that recorded at the lower frequency. The arrow indicates the artifact at the onset of the presynaptic current injection.

reduced the peak-to-peak background noise to $47 \mu \mathrm{V}$, as measured during the first $1 \mathrm{msec}$ following the coupling potential. The corresponding stained terminal and camera lucida reconstructions are in Figure 7, $B 1$ and $B 2$, respectively, which show that the gross morphological relationships are comparable to those of the chemically transmitting connection in Figure 6.

It should be noted that in 3 other experiments, it was not possible to identify the fiber studied physiologically since a second afferent was inadvertently stained as well. In these cases, both fibers terminated on the M-cell, one as a club ending and one as an endbulb. Nevertheless, the combined morphophysiological study clearly indicated that impulses in 11 club endings, as identified at the light microscopic level, mediated either dual (5) or purely electrotonic (6) transmission.

\section{Discussion}

\section{Identification of the terminals studied physiologically}

Reconstruction of dye-injected fibers indicated that the majority of the fibers recorded in our experiments terminated on the M-cell as club endings, since endbulbs were stained in only 3 out of the 14 experiments, whilc club endings were stained in all cases. This finding is consistent with the morphological observation that club endings are more numerous than endbulbs (Lin et al., 1983). In addition, endbulbs often arose from smaller-diameter axons, and the recording procedure might have preferentially selected those larger fibers that terminate as club endings. Therefore, we can confidently state that the postsynaptic potentials characterized here were representative of those mediated by club endings.

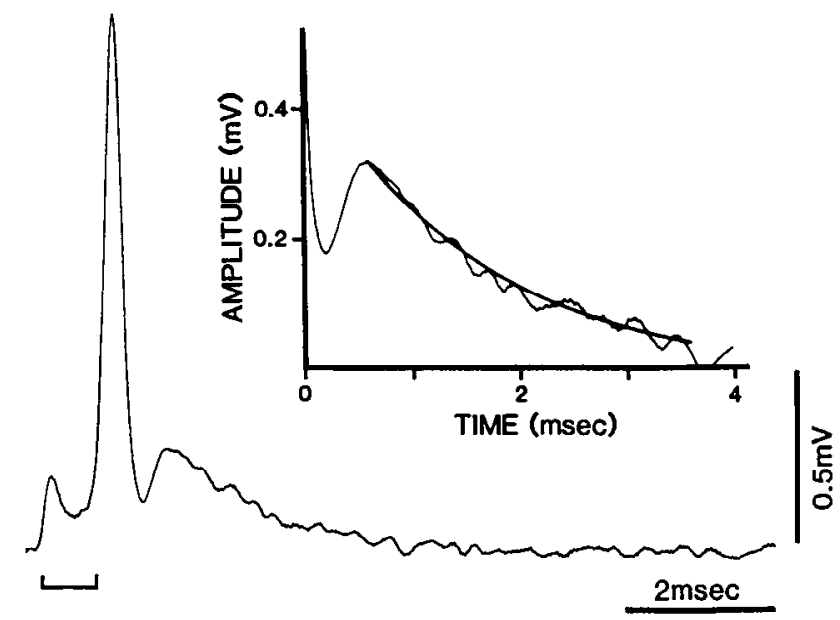

Figure 5. Exponential decay of the unitary EPSP. The example shown here is an average of 25 traces. The presynaptic axon was activated by a short current pulse, represented by the bracket, so that the complete time course of the EPSP was not interrupted. Inset, The early part of the same EPSP is expanded, and a best-fitting exponential curve, determined by regression analysis, is superimposed on the decay phase. The coefficient of determination was 0.96 , and the decay time constant, $1.5 \mathrm{msec}$. The $10-90 \%$ rise time in this example is $220 \mu \mathrm{sec}$.

\section{Low incidence of chemical transmission}

The observations that club endings can mediate either dual or purely electrotonic transmission and that the percentage of the former is less than 20 are surprising since morphological studies indicated that all the club endings have the structural correlates of chemical synapses, i.e., synaptic vesicles and pre- and postsynaptic specializations (Nakajima, 1974; Kohno and Noguchi, 1986; Tuttle et al., 1986). One possible explanation is that all the club endings mediate chemical transmission and the low incidence of observing an EPSP is simply a signal detection problem. This is not likely, because the amplitudes of the coupling potentials evoked with and without subsequent EPSPs were similar. In the case of poor signal detection due to a spatial separation of the terminal and the recording site, the amplitudes of coupling potentials associated with EPSPs would have been larger than those without EPSPs. Furthermore, the similar amplitudes of the coupling potentials also indicate that there is no significant difference in the degree of electrotonic coupling between these 2 groups of club endings. The second, and more likely, possible explanation is that the chemical synapses in the majority of the club endings are functionally silent in control conditions. Mechanisms for unblocking these synapses are discussed in the following paper (Lin and Faber, 1988).

\section{Parameters of electrotonic coupling}

Our results place the mean gap junction resistance of a single club ending in the range of 6.6-35.8 M 2 . Assuming a singlechannel resistance of $100 \mathrm{pS}$ (Loewenstein, 1975; Neyton and Trautmann, 1985; Veenstra and DeHaan, 1986), a club ending should have about 280-1500 channels open at any point in time. It should be stressed that the upper limit of 1500 is probably unrealistic, as it is based upon the unlikely assumption that the amplitude of the averaged orthodromic coupling potential underwent a maximal spatial decay. Regardless, this range is about 1-2 orders of magnitude lower than the number of intramembranous particles observed in freeze-fracture studies of club endings (34,000-100,000; mean, 58,000: Tuttle et al., 1986; 


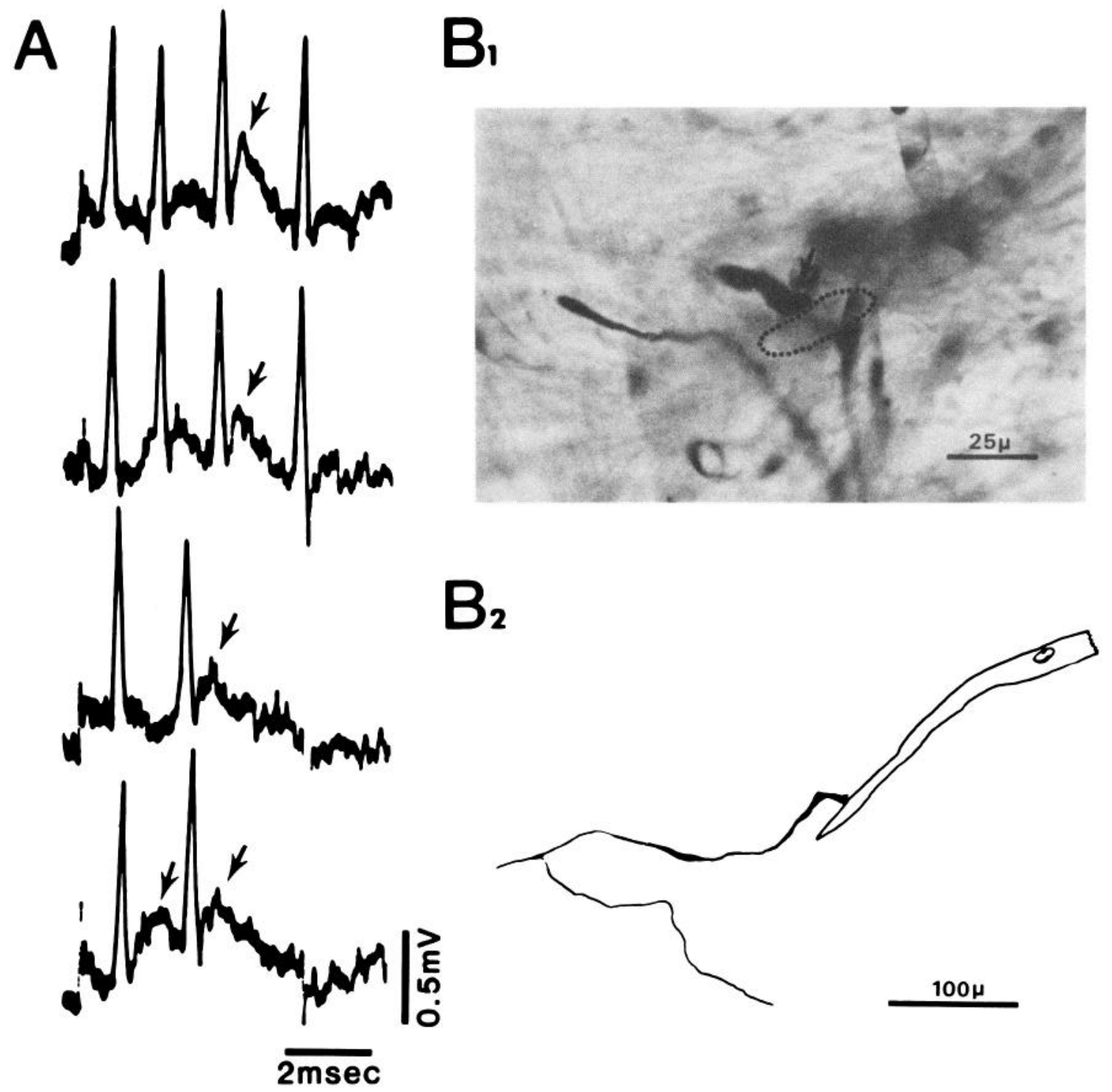

Figure 6. Example of a HRP-injected club ending that mediated both electrotonic and chemical transmission. $A$, When the saccular fiber was fired repetitively (not shown), EPSPs (arrows) of fluctuating amplitudes were clearly demonstrated in the M-cell. BI, The same fiber was also injected with HRP, and the stained terminal (arrow) had the appearance of a club ending. The lateral dendrite of the M-cell is outlined by the dotted line and could be better identified under phase-contrast optics. Another nearby stained fiber was also apparent in this micrograph, but serial reconstructions indicated that it did not make contact with the M-cell. B2, Camera lucida reconstruction of the stained saccular fiber and the M-cell lateral dendrite. The location of this club ending is about $300 \mu \mathrm{m}$ from the M-cell axon hillock. The serial reconstruction was obtained from horizontal sections, and the ventral dendrite of the M-cell was not included. The other branch of this afferent did not contact the M-cell.

24,000-121,000; mean, 64,000: Kohno and Noguchi, 1986). Before discussing the implications of this apparent mismatch between physiology and morphology, it is worthwhile to consider possible sources of error in the derived values of junctional resistance.

The estimate that junctional resistance at a club ending is between 6.6 and $35.8 \mathrm{M} \Omega$ was based on an approximation that is difficult to verify experimentally, i.e., that the amplitude of presynaptic impulses in the terminals was $75 \mathrm{mV}$. However, additional considerations support our results. First, antidromic coupling (equation 2) was not used to estimate $R_{\mathrm{j}}$ in the Results because of the uncertainty related to signal attenuation in the saccular fibers. In a few experiments, antidromic coupling potentials up to $2 \mathrm{mV}$ were recorded from saccular fibers in the medulla near the M-cell lateral dendrite. (In contrast, the av- eraged amplitude of antidromic coupling potentials was $1.1 \mathrm{mV}$ when the recording electrode was outside the brain.) If this value is used in equation (2), with $R_{\mathrm{s}}=2 R_{\mathrm{s}}{ }^{\prime}=8.4 \mathrm{M} \Omega$ and $V_{\mathrm{m}}$ (dendritic spike height) $=14.7 \mathrm{mV}, R_{\mathrm{j}}$ is equal to $13.3 \mathrm{M} \Omega$, which is comparable to the value obtained from orthodromic coupling.

Second, an independent calculation provides a lower bound for $R_{\mathrm{j}}$. In order to obtain this estimate, we assumed that the input resistance of the M-cell lateral dendrite is dominated by the gap junctions in the club endings and is $167-200 \mathrm{k} \Omega$ (Faber and Korn, 1982). Then, the termination field of the club endings on the lateral dendrite can be approximated by a cylinder 30 $\mu \mathrm{m}$ in diameter and $200 \mu \mathrm{m}$ in length (Zottoli, 1978; Lin et al., 1983), with a surface area of about $19,000 \mu \mathrm{m}^{2}$. The largest club endings revealed by freeze-fracture have a diameter of $15 \mu \mathrm{m}$ (R. Tuttle, personal communication) and a surface area of 177 


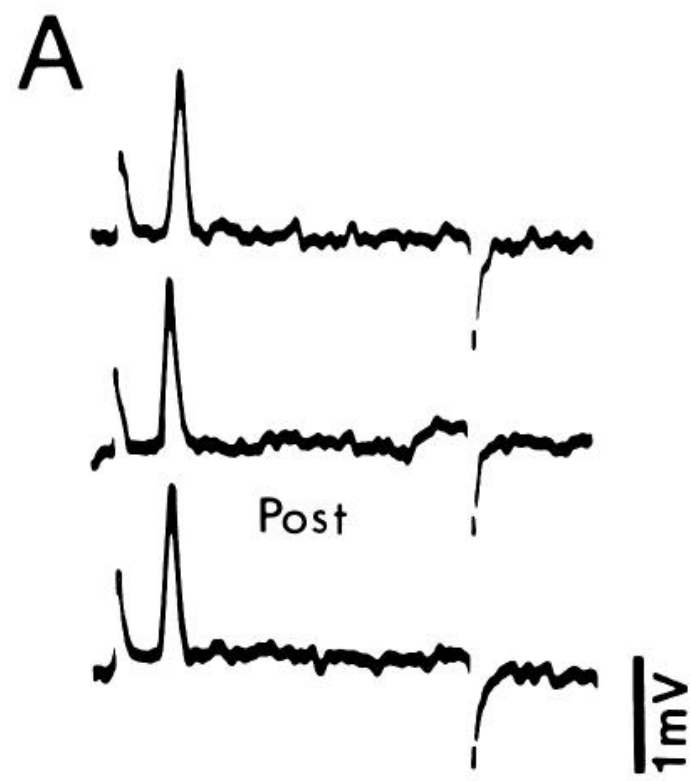

$\mathrm{B}_{1}$
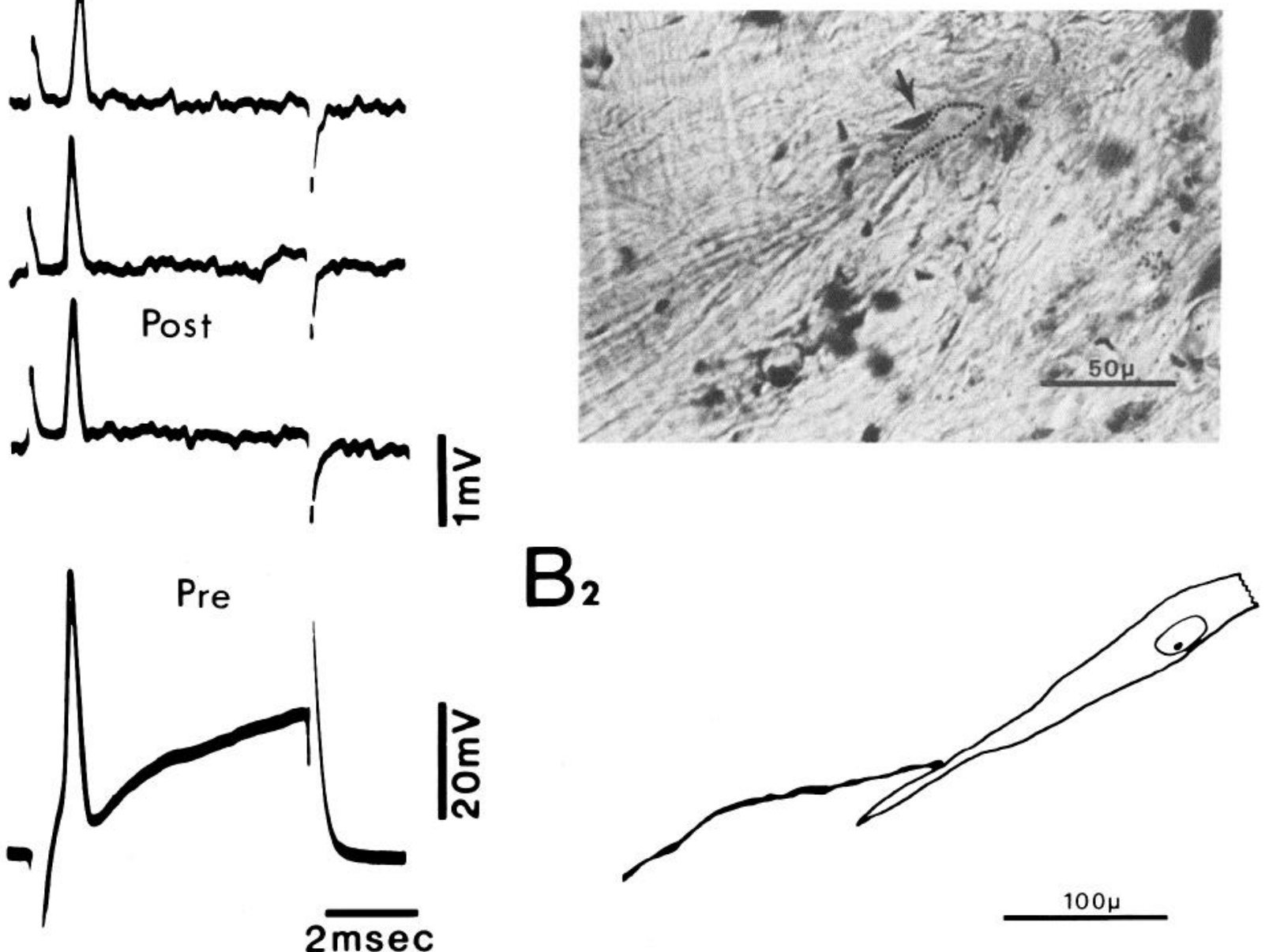

Figure 7. Example of a club ending that did not mediate chemical transmission. A, Single impulses in the saccular fiber (bottom trace, Pre) produced only electrotonic coupling potentials (upper traces, Post). The lack of a chemically mediated response is quite obvious from the single traces, and after the noise level was further reduced by signal averaging (not shown), an EPSP was still not detected. $B 1$, The same fiber shown in $A$ was injected with HRP, and the micrograph shows that its terminal has the shape and dimension of a club ending (arrow). The lateral dendrite of the M-cell is delineated by dots and can also be identified in this micrograph as a patch with a homogeneous texture. B2, Camera lucida reconstruction of the same fiber and part of the M-cell. The club ending made contact with the M-cell at a point about $225 \mu \mathrm{m}$ from the axon hillock, while the recording site (not shown) was about $280 \mu \mathrm{m}$ from the same reference point.

$\mu \mathrm{m}^{2}$. The lateral dendrite can then accommodate 100 of the largest club endings. The gap junctional resistance of individual club endings thus estimated is about $16.7-20 \mathrm{M} \Omega$, and includes 2 resistors in series, $R_{\mathrm{j}}$ and the saccular fiber extrajunctional resistance. Given the largest measured input resistances of the saccular fiber $(10.6 \mathrm{M} \Omega), R_{\mathrm{j}}$ could not be lower than $6.1 \mathrm{M} \Omega$, similar to the minimal value estimated with the other approaches. It should be stressed that the use of the M-cell somatic input resistance in this calculation inherently sets a lower bound for the estimate of $R_{\mathrm{j}}$. If the dendritic input resistance is higher than the measured $\mathrm{M}$-cell input resistance, $R_{\mathrm{j}}$ is necessarily greater.

The most reasonable explanation for the present finding is that only a small fraction $(\sim 2 \%)$ of the gap junction channels in an ending are conducting, either due to a low probability of single-channel opening or to a small fraction of the channels being in a stationary opening state. In the latter case, whether these open channels are localized to a few gap junctions or are scattered randomly throughout a terminal is not known. How- ever, it should be noted that the number of intramembranous particles within individual aggregates averaged about 380 (Tuttle et al., 1986), which is in the same range as our estimate of opened channels. Finally, the alternative that most channels are conducting and single-channel conductance is much less than $100 \mathrm{pS}$ (e.g., $1.3 \mathrm{pS}$ ) is much less likely, given the poor ion selectivity of gap junction channels and their large physical dimensions (Schwarzmann et al., 1981; Neyton and Trautmann, 1985). In summary, we conclude that the mismatch between physiology and morphology is mainly due to a low percentage of channels being open under our experimental conditions.

The observation that in 4 of 6 experiments, the variance in orthodromic coupling potentials was greater than that of the background noise, even after attempting to control for changes in M-cell input resistance spike height (Fig. 3), may be related to this conclusion. This disparity, which did not appear in the other electrotonic junctions analyzed in this manner (Shapovalov and Shiriaev, 1980), would not be expected if the junctional channels had a high probability of being open. We therefore performed Poisson analysis of the coupling potential amplitude fluctuations, after subtracting the variance of the noise from that 
of the signal, and obtained average values for the mean quantal content of 240 (Lin, 1986). This quantal content, which would correspond to the average number of conducting junctional units, is comparable to the lower limit calculated from the estimates of $R_{\mathrm{j}}$.

\section{Possible electrophysiological consequences of varying the fraction of opened gap junction channels}

Altering the degree of coupling between afferent endings and the $\mathrm{M}$-cell might not necessarily modify the orthodromic transmission of electrical signals. That is, if the fraction of open gap junction channels in all club endings were increased by an order of magnitude, the amplitude of unitary orthodromic coupling potentials might not change. This is because, although the lowered junctional resistance would increase current flowing from individual afferents to the lateral dendrite, the consequent decrease in $\mathrm{M}$-cell regional input resistance would tend to offset this effect, assuming that the local input resistance is dominated by the gap junctions. A quantitative model is necessary to further evaluate this argument and to estimate the concomitant change of the space constant. Nevertheless, it is conceivable that in this system metabolic coupling via gap junctions may be changed without significant conscquences for the processing of electrical signals. At the same time, chemically mediated EPSPs might be selectively attenuated by a decrease in junctional resistance, but postsynaptic potential changes could more effectively influence the presynaptic terminals under such conditions.

\section{EPSP properties}

Given the fast time constant of the M-cell membrane, the average decay time constant of the EPSP $(1.32 \mathrm{msec})$ mediated by club endings should approximate that of the synaptic current. This decay is $2-3$ times longer than those of unitary responses recorded at Ia-motoneuron synapses (0.3-0.4 msec in Finkel and Redman, 1983) and at synapses between cultured spinal neurons $(0.6 \mathrm{msec}$ in Nelson et al., 1986). The longer time constant of the synaptic current (or conductance) mediated by club endings might compensate for the fast membrane time constant of the $M$-cell, so that the resultant potential change can have a reasonable duration. On the other hand, the synaptic current produced by mossy fibers in the guinea pig hippocampal CA3 neuron has an even longer decay time constant, 3-4 msec (Brown and Johnston, 1983). Therefore, the time course of a central excitatory synaptic current may be "tailored" such that both the passive properties of the postsynaptic cell and the requirements for information processing are taken into consideration. Furthermore, because of the longer time course of the EPSP relative to that of the associated coupling potential, the charge transfer produced by the 2 is similar, although the amplitude of the latter is typically 6 times that of the EPSPs.

The amplitude of the underlying synaptic current $\left(I_{\mathrm{s}}\right)$ and conductance change $\left(G_{\mathrm{s}}\right)$ of an EPSP mediated by a single club ending can be estimated using the assumptions that the fast time constant of the M-cell does not significantly attenuate the EPSP amplitude capacitatively and that the reversal potential of the response is around $0 \mathrm{mV}$. The mean values of $I_{\mathrm{s}}$ and $G_{\mathrm{s}}$ thus calculated are $0.7 \mathrm{nA}$ and $8.8 \mathrm{nS}$, respectively. However, as spatial decay of the EPSP may result in an underestimation of these parameters, values obtained from the largest EPSP, 1.5 $\mathrm{nA}$ and $18.8 \mathrm{nS}$, may be more realistic. The latter estimates are similar to those obtained for Ia-motoneuron synapses, $1.3 \mathrm{nA}$ and $23.5 \mathrm{nS}$ (Finkel and Redman, 1983). In contrast, the corresponding maximal values for synapses between cultured spinal neurons are much larger, $4 \mathrm{nA}$ and $89 \mathrm{nS}$, respectively (Nelson et al., 1986). The similarity between maximal $I_{\mathrm{s}}$ and $G_{\mathrm{s}}$ for club endings and Ia-motoneuron synapses may be fortuitous since the variables that determine the unitary conductance change include the number of release sites, the quantal amplitude, the probability of release, and the type of synaptic channels involved. Therefore, a more elementary parameter for comparison may be the conductance change associated with a single quantum, which is mainly determined by the quantity of transmitter released and the type and number of postsynaptic receptors (see Lin and Faber, 1988).

\section{References}

Adams, J. C. (1981) Heavy metal intensification of DAB-based HRP reaction product. J. Histochem. Cytochem. 29: 775.

Asada, Y., and M. V. L. Bennett (1971) Experimental alteration of coupling resistance at an electrotonic synapse. J. Cell Biol. 49: 159172.

Barr, L., M. M. Dewey, and W. Berger (1965) Propagation of action potentials and the structure of the nexus in cardiac muscle. J. Gen. Physiol. 48: 797-823.

Bennett, M. V. L. (1966) Physiology of electrical junctions. Ann. NY Acad. Sci. 137: 509-539.

Bennett, M. V. L. (1977) Electrical transmission, a functional analysis and comparison to chemical transmission. In Handbook of Physiology. The Nervous System, Sec. 1, Vol. 1, Pt. 1, Chap. 11, pp. 357416, American Physiological Society, Bethesda, MD

Bennett, M. V. L., Y. Nakajima, and G. D. Pappas (1967a) Physiology and ultrastructure of electrotonic junctions. III. Giant electromotor neurons of Malapterurus electricus. J. Neurophysiol. 30: 209-235.

Bennett, M. V. L., G. D. Pappas, M. Gimenez, and Y. Nakajima (1967b) Physiology and ultrastructure of electrotonic junctions. IV. Medullary electromotor nuclei in gymotid fish. J. Neurophysiol. 30: 236-300.

Brown, T. H., and D. Johnston (1983) Voltage-clamp analysis of mossy fiber synaptic input to hippocampal neurons. J. Neurophysiol. 50: 487-507.

Crank, W. D. (1986) Cable models of the goldfish Mauthner cell. Ph.D. thesis, SUNY at Buffalo, Buffalo, NY.

Diamond, J. (1968) The activation and distribution of GABA and L-glutamate receptors on goldfish Mauthner neurons: An analysis of dendritic remote inhibition. J. Physiol. (Lond.) 194: 669-723.

Faber, D. S., and H. Korn (1982) Transmission at a central inhibitory synapse. I. Magnitude of the unitary postsynaptic conductance change and kinetics of channel activation. J. Neurophysiol. 48: 654-678.

Faber, D. S., and H. Korn (1986) Instantaneous inward rectification in the Mauthner cell: A postsynaptic booster for excitatory inputs. Neuroscience 9: 1037-1043.

Faber, D. S., and S. J. Zottoli (1981) Axotomy-induced changes in cell structure and membrane excitability are sustained in a vertebrate central neuron. Brain Res. 223: 436-443.

Faber, D. S., C. Kaars, and S. J. Zottoli (1980) Dual transmission at morphologically mixed synapses: Evidence from postsynaptic cobalt injections. Neuroscience 5: 433-440.

Finkel, A. S., and S. J. Redman (1983) The synaptic current evoked in cat spinal motoneurones by impulses in single group Ia axons. J. Physiol. (Lond.) 342: 615-632.

Flagg-Newton, J. L., G. Dahl, and W. R. Loewenstein (1981) Cell junction and cyclic AMP: I. Upregulation of junctional membrane permeability and junctional membrane particles by administration of cyclic nucleotide or phosphodiesterase inhibitor. J. Membr. Biol. 63: 105-121.

Fukami, Y., T. Furukawa, and Y. Asada (1965) Excitability changes of the Mauthner cell during collateral inhibition. J. Gen. Physiol. 48 . $581-600$

Furshpan, E. J. (1964) "Electrical transmission" at an excitatory synapse in a vertebrate brain. Science 144: 878-880.

Furshpan, E. J., and T. Furukawa (1962) Intracellular and extracellular responses of the several regions of the Mauthner cell of the goldfish. J. Neurophysiol. 25: 732-771.

Furukawa, T. (1966) Synaptic interaction at the Mauthner cell of goldfish. Prog. Brain Res. 21A: 44-70.

Haas, H. G., R. Meyer, H. M. Einwachter, and W. Stockem (1983) 
Intercellular coupling in frog heart muscle: Electrophysiological and morphological aspects. Pfluegers Arch. 399: 321-335.

Hackett, J. T., and A. Buchheim (1984) Ultrastructural correlates of electrical-chemical transmission in goldfish cranial motor nuclei. $\mathrm{J}$. Comp. Neurol. 224: 425-436.

Hama, K. (1961) Some observations on the fine structure of the giant fibers of the crayfish (Cambarus virilus and Cambarus clarkii) with special reference to the submicroscopic organization of the synapses. Anat. Rec. 14I: 275-293.

Johnson, R., M. Hammer, J. Sheridan, and J.-P. Revel (1974) Gap junction formation between reaggregated Novikoff hepatoma cells. Proc. Natl. Acad. Sci. USA 71: 4536-4540.

Kohno, K., and N. Noguchi (1986) Large myelinated club endings on the Mauthner cell in the goldfish: A study with thin sectioning and freeze-fracturing. Anat. Embryol. 173: 361-370.

Korn, H., and D. S. Faber (1975) An electrically mediated inhibition in goldfish medulla. J. Neurophysiol. 38: 452-471.

Lee, S.-H., and F. B. Krasne (1984) Microanatomy of synapses processing input to the lateral giant axons of the crayfish. Soc. Neurosci. Abstr. 10: 218.6.

Lin, J.-W. . (1986) Physiology and morphology of identified mixed excitatory synapses on the goldfish Mauthner cell. Ph.D. thesis, SUNY at Buffalo, Buffalo, NY.

Lin, J.-W., and D. S. Faber (1988) Synaptic transmission mediated by single club endings on the goldfish Mauthner cell. II. Plasticity of excitatory postsynaptic potentials. J. Neurosci. 8: 1313-1325.

Lin, J.-W., D. S. Faber, and M. R. Wood (1983) Organized projection of the goldfish saccular nerve onto the Mauthner cell lateral dendrite. Brain Res. 274: 319-324.

Loewenstein, W. R. (1975) Permeable junctions. Cold Spring Harbor Symp. Quant. Biol, 40: 49-63.

Loewenstein, W. R. (1981) Junctional intercellular communication: The cell-to-cell membrane channel. Physiol. Rev. 61: 829-913.

Martin, A. R., and G. Pilar (1963) Dual mode of synaptic transmission in the ciliary ganglion. J. Physiol. (Lond.) 168: 443-463.

Nakajima, Y. (1974) Fine structure of the synaptic endings on the Mauthner cell of the goldfish. J. Comp. Neurol. 156: 375-402.

Nakajima, Y., and K. Kohno (1978) Fine structure of the Mauthner cell: Synaptic topography and comparative study. In Neurobiology of the Mauthner Cell, D. S. Faber and H. Korn, eds., pp. 133-166, Raven, New York.

Nelson, P. G., R. Y. K. Pun, and G. L. Westbrook (1986) Synaptic excitation in cultures of mouse spinal cord neurons: Receptor pharmacology and behaviour of synaptic current. J. Physiol. (Lond.) 372: 169-190.

Neyton, J., and A. Trautmann (1985) Single-channel currents of an intercellular junction. Nature 317: 331-335.

Neyton, J., and A. Trautmann (1986) Acctylcholinc modulation of the conductance of intercellular junctions between rat lacrimal cells. J. Physiol. (Lond.) 377: 283-295.

Pappas, G. D., and S. G. Waxman (1972) Synaptic fine structuremorphological correlates of chemical and electrotonic transmission. In Structure and Function of Synapses, G. D. Pappas and D. P. Purpura, eds., pp. 1-43, Raven, New York.

Pappas, G. D., Y. Asada, and M. V. L. Bennett (1971) Morphologica correlates of increased coupling resistance at an electrotonic synapse. J. Cell Biol. 49: 173-188.
Peracchia, C. (1977) Gap junctions: Structural changes after uncoupling procedures. J. Cell Biol. 72: 628-641.

Peracchia, C., and A. Dulhunty (1976) Low resistance junctions in crayfish. Structural changes with functional uncoupling. J. Cell Biol. 70: 419-439.

Robertson, J. D., T. S. Bodenheimer, and D. E. Stage (1963) The ultrastructure of Mauthner cell synapses and nodes in goldfish brain. J. Cell Biol. 19: 159-199.

Rovainen, C. M. (1974a) Synaptic interactions of identified nerve cells in the spinal cord of the sea lamprey. J. Comp. Neurol. 154: 189206.

Rovainen, C. M. (1974b) Synaptic interactions of reticulospinal neurons and nerve cells in the spinal cord of the sea lamprey. J. Comp. Neurol. 154: 207-223.

Schwarzmann, G., H. Wiegandt, B. Rose, A. Zimmerman, D. BenHaim, and W. R. Loewenstein (1981) Diameter of the cell-to-cell junctional membrane channels as probed with neutral molecules. Science 213: 551-553.

Shapovalov, A. I. (1980) Interneuronal synapses with electrical, dual and chemical mode of transmission in vertebrates. Neuroscience 5: $1113-1124$.

Shapovalov, A. I., and B. I. Shiriaev (1980) Dual mode of junctional transmission at synapses between single primary afferent fibers and motoneurones in the amphibian. J. Physiol. (Lond.) 306: 1-15.

Sotelo, C., and H. Korn (1978) Morphological correlates of electrical and other interactions through low-resistance pathways between neurons of the vertebrate central nervous system. Int. Rev. Cytol. 55: 67-107.

Spray, D. C., J. C. Saez, D. Brosius, M. V. L. Bennett, and E. L. Hertzberg (1986) Isolated liver gap junctions: Gating of transjunctional currents is similar to that in intact pairs of rat hepatocytes. Proc. Natl. Acad. Sci. USA 83: 5494-5497.

Takahashi, K., and K. Hama (1965) Some observations on the fine structure of the synaptic area in the ciliary ganglion of the chick. $Z$. Zellforsch. 67: 174-184.

Taugner, R., U. Sonnhof, D. W. Richter, and A. Schiller (1978) Mixed (chemical and electrical) synapses on frog spinal motoneurons. Cell Tissue Res. 193: 41-59.

Tokunaga, A., K. Akert, C. Sandri, and M. V. L. Bennett (1980) Cell types and synaptic organization of the medullary electromotor nucleus in a constant frequency weakly electric fish, Sternarchus albifrons. J. Comp. Neurol. 192: 407-426.

Tuttle, R., S. Masuko, and Y. Nakajima (1986) Freeze-fracture study of the large myelinated club ending synapse on the goldfish Mauthner cell: Special reference to the quantitative analysis of gap junctions. $\mathbf{J}$. Comp. Neurol. 246: 202-211.

Veenstra, R. D., and R. L. DeHaan (1986) Single gap junctional channcl activity in embryonic chick heart cells. Biophys. J. 49: 343a.

Watanabe, A., and H. Grundfest (1961) Impulse propagation at the septal and commissural junctions of crayfish lateral giant axons. J. Gen. Physiol. 45: 267-308.

Zottoli, S. J. (1978) Comparative morphology of the Mauthner cell in fish and amphibians. In Neurobiology of the Mauthner Cell, D. S. Faber and H. Korn, eds., pp. 13-45, Raven, New York.

Zucker, R. S. (1972) Crayfish escape behavior and central synapses. I. Neural circuit exciting lateral giant fiber. J. Neurophysiol. 35: 599_ 620. 